\title{
The Relationship Between Statistics Anxiety and Attitudes Toward Statistics
}

\author{
Mustafa BALOĞLU* Recep KOÇAK $^{* * *}$ Paul F. ZELHART ${ }^{* *}$
}

\begin{abstract}
As the applications of statistical techniques have increased, studies that investigate the problems faced while teaching statistics have increased as well. However, most problems faced in statistics teaching are not due to cognitive deficiencies but may be due to attitudinal factors such as statistics anxiety. In the present study, the relationship between statistics anxiety and attitudes towards statistics anxiety was investigated by canonical correlation techniques. The sample of the study consisted of 95 seniors and 55 graduate students in social sciences. Students answered the Statistical Anxiety Rating Scale and Attitudes Towards Statistics scale. Results showed that seniors and graduate students did not differ significantly in terms of the study variables and that statistics anxiety and attitudes towards statistics were related.
\end{abstract}

Key Words: Statistics Anxiety, Attitudes Towards Statistics, Canonical Correlation

\footnotetext{
* Doç. Dr. Gaziosmanpaşa Üniversitesi Eğitim Fakültesi Eğitim Bilimleri Bölümü TOKAT E-mail: baloglu@gop.edu.tr Tel:0356 2521616/3415

** Prof. Dr. Texas A\&M University College of Education Department of Psychology Commerce, TX USA

*** Yrd. Doç. Dr. Gaziosmanpaşa Üniversitesi Eğitim Fakültesi Eğitim Bilimleri Bölümü TOKAT E-mail: recepkocak@gop.edu.tr Tel:0356 2521616/3413

Paul_Zelhart@tamu-commerce.edu +1903 8861837
} 


\section{SUMMARY}

\section{Introduction}

Because the importance and applications of statistics have increased in recent years (Connor-Greene, 1993; Fenster, 1992), researchers have had to address difficulties as they arose. In this vein, most attempts have focused on a cognitive array of statistics instruction, paying little attention to noncognitive factors. However, many of the difficulties in statistics courses may not be a result of insufficient aptitude; rather, they may be reflections of attitudinal factors such as anxiety related to statistics (Baloğlu, 2001; Onwuegbuzie, 1998b). Statistics anxiety is newly defined as a state anxiety in the literature. Onwuegbuzie, DaRos, and Ryan (1997) defined statistics anxiety as "a state-anxiety reaction to any situation in which a student is confronted with statistics in any form and at any time" (p. 28).

The "causes" of statistics anxiety are usually clustered around three major factors: dispositional, situational, and environmental (Baloğlu, 2001). Dispositional factors include psychological and emotional characteristics such as attitudes toward statistics, perceptions (Zeidner, 1991), self- concept (Onwuegbuzie, 1993), and learning styles (Onwuegbuzie, 1998a). Situational factors of statistics anxiety are immediate factors that result from statistics courses and include, but not limited to, statistics teachers (Zeidner, 1991), nature of statistics courses (Fenster, 1992), lack of feedback from statistics instructors, pace of statistics instruction, and statistical terminology.

Environmental causes are factors that "have affected the individual prior to the statistics course" and include gender, age, ethnicity, academic major, and previous mathematics experiences. Gender is one of the most widely investigated environmental variables in statistics anxiety research. In general, women have been reported to encounter more difficulties in quantitative areas (Royse \& Rompf, 1992). Similarly, Zeidner (1991) and Onwuegbuzie $(1993,1995)$ reported that women experienced higher levels of statistics anxiety than did men in their studies. However, other studies failed to find significant differences between men and women regarding statistics anxiety levels (Baloğlu, 2001). Auzmendi (1991) found that both the number of years of mathematics courses taken and the presence or absence of prior statistics course experience were significant predictors of statistics anxiety. Zeidner (1991) reported that mathematical skills and the number of completed mathematics courses were relevant to statistics anxiety.

One's age and educational level are also hypothesized as environmental causes of statistics anxiety. Onwuegbuzie (1998a) and Royse and Rompf (1992) found that older students experienced more statistics anxiety than their younger counterparts. Finally, Feinberg and Halperin (1978), Woehlke 
and Leitner (1980), and Baloğlu (2001) found that previous mathematics experiences and statistics anxiety were related.

The purpose of the present study was to investigate the relationship between college students' attitudes toward statistics and their anxiety levels. The relation between the six dimensions of statistics anxiety (Worth of Statistics, Interpretation Anxiety, Test and Class Anxiety, Computational Self-concept, Fear of Asking for Help, and Fear of Statistics Teachers) and two dimensions of attitudes toward statistics (Course and Field) was investigated by canonical correlation analysis.

\section{Method}

The working population of the present study was students enrolled in colleges in Texas. By using convenient sampling technique, 150 volunteer students were selected for the study. Ninety five of these students were seniors and 55 were graduate students. Students' ages ranged from 18 to 54 $($ mean $=28, \mathrm{SD}=9)$. Participants responded to the Statistical Anxiety Rating Scale (Cruise et al., 1985) and the Attitudes Toward Statistics Scale (Wise, 1985). Information about the psychometric properties of these scales were present in literature.

The STARS, a 51-item, 5-point, Likert-type instrument, was developed to measure statistics anxiety in two parts (Cruise et al., 1985). The first part includes 23 statements that are related to statistics anxiety and the second part includes 28 items that are related to dealing with statistics. These two parts make up the instrument's six subscales: Worth of Statistics, Interpretation Anxiety, Test and Class Anxiety, Computational Self-concept, Fear of Asking for Help, and Fear of Statistics Teachers. The total STARS score is obtained by summing the six subscale scores, and varies between 51 and 255. Initial psychometric properties of the STARS were reported by Cruise et al. (1985). Ten statistics instructors' /doctoral students' coefficients of agreement scores as to which item belonged to which of the six subscales ranged from .60 to 1.00 , with a mean of .91 , thus showing a strong content validity. Construct validity of the instrument was investigated through a principal component analysis with a varimax rotation. Analysis from 1,150 students resulted in six factors, whose loadings varied between .48 and .86 (Cruise et al., 1985). By using the data from 537 students, the STARS' concurrent validity was found by correlating it with the MAS $(\underline{r}=.76, \underline{p}<$ .01 ). Cruise et al. (1985) found that internal consistency coefficients of the six subscales ranged from .68 to .94 , with a median of .88 (.94 for Worth of Statistics, .87 for Interpretation Anxiety, .68 for Test and Class Anxiety, .88 for Computational Self-concept, .89 for Fear of Asking for Help, and .80 for Fear of Statistics Teachers). 
The ATS was developed by Wise (1985) to measure students' attitudes toward statistics under two parts. Part one is related to attitudes toward the field of statistics (Field) and includes 20 items (1 through 20). Part two consists of 9 items (21 through 29) and is related to students' attitudes toward statistics courses (Course). Psychometric properties of the ATS were reported by Wise (1985). A two-week test-retest reliability of the ATS was found to be .82 for the Course subscale and .90 for the Field subscale. Initial coefficient alpha reliability was .92 for the Course subscale and .90 for the Field subscale (Wise, 1985). Additional coefficient alpha reliabilities for the total ATS was shown to be .95 in the pre-test (.94 for the Field and .93 for the Course subscales) and .92 in the post-test (.91 for the Field and .85 for the Course).

\section{Results}

The relation between the six dimensions of statistics anxiety (Worth of Statistics, Interpretation Anxiety, Test and Class Anxiety, Computational Self-concept, Fear of Asking for Help, and Fear of Statistics Teachers) and two dimensions of attitudes toward statistics (Course and Field) was investigated by Pearson correlation coefficient (Table 1).

Table 1. Relations Between Statistics Anxiety and Attitudes Toward Statistics Total and Subscale Scores

\begin{tabular}{|c|c|c|c|c|c|c|c|c|c|}
\hline & \multicolumn{9}{|c|}{ Değişkenler } \\
\hline & 1. & 2. & 3. & 4. & 5. & 6. & 7. & 8. & 9. \\
\hline 1.Statistics Anxiety & - & & & & & & & & \\
\hline $\begin{array}{l}\text { 2. Attitudes Toward } \\
\text { Statistics }\end{array}$ & .72 & - & & & & & & & \\
\hline 3. Worth of Statistics & .85 & .84 & - & & & & & & \\
\hline 4. Interpretation Anxiety & .76 & .36 & .41 & - & & & & & \\
\hline 5. Test and Class Anxiety & .79 & .45 & .49 & .69 & - & & & & \\
\hline 6. Compt. Self Concept & .85 & .63 & .73 & .54 & .59 & - & & & \\
\hline $\begin{array}{l}\text { 7. Fear of Asking for } \\
\text { Help }\end{array}$ & .65 & .29 & .38 & .63 & .52 & .50 & - & & \\
\hline $\begin{array}{l}\text { 8. Fear of Statistics } \\
\text { Teachers }\end{array}$ & .74 & .50 & .64 & .44 & .47 & .62 & .43 & - & \\
\hline 9. Attitude-Statistics Field & .52 & .93 & .74 & .18 & .26 & .44 & .14 & .35 & - \\
\hline $\begin{array}{l}\text { 10. Attitude-Statistics } \\
\text { Course }\end{array}$ & .82 & .81 & .75 & .55 & .63 & .75 & .45 & .59 & .54 \\
\hline
\end{tabular}

All correlations are significant

In order to find the relationship between a group of statistics anxiety variables and a group of attitudes toward statistics variables was investigated by SPSS-CANCORR function. Statistics anxiety set was composed of worth of statistics, interpretation anxiety, test and class anxiety, computational self- 
concept, fear of asking for help, and fear of statistics teachers variables. Attitudes toward statistics set was composed of attitudes toward statistics course and attitudes toward statistics field variables. The results of the canonical analysis was presented in Table 2. Shortly, results indicate that two sets are related.

Table 2. Correlations Between the Anxiety and Attitude Variables, Standardized Canonic Coefficients, Canonical Correlations, Percent of Variances, Redundancies.

\begin{tabular}{lcccc}
\hline & \multicolumn{2}{c}{ 1. Canonical Variable } & \multicolumn{2}{c}{ 2. Canonical Variable } \\
\cline { 2 - 5 } & Correlation & Coefficient & Correlation & Coefficient \\
\hline Anxiety Set & & & & \\
Worth of statistics & -.97 & -.76 & -.22 & -1.24 \\
Interpretation Anxiety & -.55 & -.06 & .56 & .23 \\
Test/Class Anxiety & -.65 & -.17 & .53 & .35 \\
Computational self Concept & -.84 & -.21 & .38 & .67 \\
Fear of Asking for Help & -.44 & .06 & .48 & .15 \\
Fear of Statistics Teachers & -.66 & .03 & .28 & .34 \\
Variance Percent & .50 & & .18 & Total $=.68$ \\
Redundancy & .37 & & .06 & Total $=.43$ \\
Attitude Set & & & & \\
Field & -.79 & -.40 & -.61 & -1.12 \\
Course & -.94 & -.73 & .33 & .94 \\
Variance Percent & .76 & & .24 & Total $=1.0$ \\
Redundancy & .56 & & .08 & Total $=.64$ \\
Canonical Correlation & .86 & & .57 & \\
\hline
\end{tabular}

\section{Discussion}

Statistics anxiety has been identified as a multidimensional construct in the literature. Similarly, attitudes toward statistics have two dimensions. When the variables in investigation have more than one dimensions, the relationship between the two can be investigated by canonical correlation method. Thus, the present study used canonical correlation techniques to investigate a set of statistics anxiety variables' relationship with a set of attitudes variables. The sample size and other parametric assumptions have been check before the analyses. Results showed significant statistical relationships between the two sets. This means that statistics anxiety and attitudes toward statistics are highly related, which is a confirmation of previous studies in the literature (e.g., Wise, 1985; Zanakis \& Valenzi, 1997). The highest relationship was found between the worth of statistics, computational-self and attitudes toward statistics course. This may mean that quite a bit amount of computations are done in statistics courses and students have negative feelings toward computations in statistics courses. Less 
emphasis on the computational part and more emphasis on the practical usage of the statistical techniques being taught may be a useful suggestion.

As a conclusion, we can say that negative attitudes toward statistics field and more specifically statistics courses trigger anxiety among students in these courses. Therefore, the first job for a statistics instructor should be focusing on students attitudes in the beginning of the course before going into lectures. More suggestions along this line can be found in the literature (e.g., Baloğlu, 2001; Blalock, 1987). Finally, more research in the area of statistics anxiety is necessary. 


\section{İstatistik Kaygısı ve İstatistiğe Yönelik Tutumlar Arasındaki İlişki}

\section{Mustafa BALOĞLU* Recep KOÇAK ${ }^{* * *}$ Paul F. ZELHART ${ }^{* *}$}

Öz. Günümüzde istatistik uygulamalarının öneminin artmasıyla araştırmacıların istatistik öğreniminde karşılaşılan engelleri ortaya çıkarma ve bunlarla başa çıkma yolları üzerindeki çalışmalarının da arttığı görülmektedir. İstatistik öğreniminde karşılaşılan sorunların çoğu bilişsel yetersizliklerden kaynaklanıyor görünmesine rağmen sorunlar çoğunlukla istatistik kaygısı gibi tutumsal (duyuşsal) nedenlere dayanmaktadırlar. Bu çalışmada, istatistik derslerinde öğrenciler üzerinde gözlemlenen istatistik kaygısı ile öğrencilerin istatistik alanı ve derslerine yönelik olan tutumları kanonik korelasyon yöntemiyle incelenmiştir. Araştırmanın örneklemini istatistiğe giriş dersini alan 95 üniversite son sınıf öğrencisi ile 55 yüksek lisans öğrencisi oluşturmuştur. Öğrenciler İstatistik Kaygısı Derecelendirme Ölçeği ve İstatistiğe Karşı Tutumlar Ölçeği’ni yanıtlamışlardır. Bulgular üniversite son sınıf ile yüksek lisans öğrencilerinin araştırma değişkenleri ve demografik değişkenler boyutunda farklı olmadığını göstermektedir. Sonuçlar istatistiğe karşı takınılan tutumlar ile istatistik kaygısı arasındaki ilişkinin anlamlı düzeyde olduğu yönündedir.

Anahtar Kelimeler: İstatistik Kaygısı, İstatistiğe Karşı Tutumlar, Kanonik Korelasyon

\footnotetext{
* Doç. Dr. Gaziosmanpaşa Üniversitesi Eğitim Fakültesi Eğitim Bilimleri Bölümü TOKAT E-mail: baloglu@gop.edu.tr Tel:0356 2521616/3415

** Prof. Dr. Texas A\&M University College of Education Department of Psychology Commerce, TX USA Paul_Zelhart@ tamu-commerce.edu +1903 8861837

*** Yrd. Doç. Dr. Gaziosmanpaşa Üniversitesi Eğitim Fakültesi Eğitim Bilimleri Bölümü TOKAT E-mail: recepkocak@gop.edu.tr Tel:0356 2521616/3413
} 


\section{GİRis}

Günümüzde istatistik ve uygulamalarının öneminin artmasıyla birlikte araştırmacıların istatistik öğretiminde karşılaşılan engelleri ortaya çıkarma ve bunlarla başaçıkma yolları üzerindeki çalışmalarının da arttığı görülmektedir (Connor-Greene, 1993; Fenster, 1992). Bu tür çalışmaların çoğu istatistik kaygısına neden olan bilişsel olmayan faktörleri incelemişlerdir. Fakat istatistik öğreniminde karşılaşılan sorunların pek çoğu bilişsel yetersizliklerden ortaya çıkmasına rağmen sorunların kökeni çoğunlukla istatistik kaygısı gibi tutumsal nedenlere dayanmaktadırlar (Baloğlu, 2001; Onwuegbuzie, 1998b).

$\mathrm{Bu}$ amaçla, istatistik kaygısı adında ve diğer kaygı türlerinden faklı olarak yeni bir durumsal kayg1 tanımını literatürde görmekteyiz. Onwuegbuzie, DaRos ve Ryan (1997) istatistik kaygısını "istatistik derslerinde veya istatistiksel işlemler yaparken, örneğin veri toplarken, verileri analiz ederken veya verilerin sonuçlarını yorumlarken, karşılaşılan durumsal kaygı reaksiyonu"(tepkisel davranış) olarak tanımlamışlardır (s. 28).

Yeni tanımlanan bu kaygının nedenleri üç ana başlık altında incelenmiştir: Kişisel, durumsal ve çevresel nedenler (Baloğlu, 2001). Bireysel nedenler boyutunda, algılama, tutumlar, benlik saygıs1, öğrenme sitilleri ve genel kaygi düzeyi gibi psikolojik ve duygusal faktörler sıralanabilir. Örneğin, Swanson, Meinert ve Swanson (1994) ile Zanakis ve Valenzi (1997) öğrencilerin istatistik derslerine yönelik genelde olumsuz bir tutum takındıklarını ve bunun da istatistik kaygısını arttırdığını saptamışlardır. Durumsal nedenler ise istatistik dersini veren eğitmen, istatistik dersinin yapısı, derste edinilen geribildirim, dersin işlenme hızı ve derste kullanılan terminoloji gibi doğrudan olarak dersle ilgili nedenlerdir. Nitel bir çalışmada, Onwuegbuzie ve diğerleri (1997) geribildirim ve cesaretlendirme eksikliklerinin öğrencilerde dersle ilgili olumsuz algılamalara neden olduğunu ve dolayısıyla istatistik kaygısını arttırdığını bulmuşlardır. Aynı çalışmada, öğrencilerin genelde istatistik derslerini çok hızlı işlenen dersler olarak algıladıkları ve bunun da onların bu dersteki kaygılarını arttırdığı saptanmıştır. Bireylerin cinsiyet, yaş, akademik bölüm, geçmiş matematik dersi deneyimleri gibi kişiye has nedenler çevresel nedenler grubunda toplanmıştır. Onwuegbuzie (1995) ve Zeidner (1991) kadınların erkeklere oranla daha yüksek düzeyde istatistik kaygıs1 yaşadıklarını bulmalarına rağmen; Baloğlu (2001) iki grup arasında istatistiksel açıdan anlamlı kaygı farklılığa rastlamamıştır. Auzmendi (1991) ise daha önce alınan matematik ders sayısının istatistik kaygısını tahmin etmede manidar bir değişken olduğunu saptamıştır. Öğrencilerin yaşları ile onların kaygı düzeyleri arasındaki ilişkiyi inceleyen Onwuegbuzie (1998b) ve Royse ve Rompf (1992), yaşlı ögrencilerin gençlere oranla daha fazla 
istatistik kaygısı taşıdıklarını bulmuşlardır. Son olarak da, Baloğlu (2001) ve Woehlke ve Leitner (1980) eski matematik tecrübelerinin istatistik kaygis1 ile olumsuz yönde ilişkili olduğunu bulmuşlardır.

$\mathrm{Bu}$ çalışmanın amacı lisans son sınıf ve yüksek lisans öğrencilerinin istatistik kaygısı düzeyleri ile onların istatistiğe karşı olan tutumları arasındaki ilişkiyi incelemektir. İstatistik kaygısının altı boyutu (istatistik değeri, yorumlama kaygısı, test ve sinıf kaygısı, hesaplama, yardım isteme korkusu, istatistik öğreticisi korkusu) ile istatistiğe karş1 tutumların iki boyutu (istatistik alanına ve istatistik derslerine yönelik tutumlar) arasındaki ilişki incelendiğinden kanonik korelasyon analizi kullanılmıştır.

\section{YÖNTEM}

\section{Örneklem}

Araştırmanın evreninin Amerika Birleşik Devletleri'nin Teksas eyaletinde yüksek öğrenim görmekte olan öğrenciler oluşturmaktadır. $\mathrm{Bu}$ evrenin içinden istatistiğe giriş derslerini gönüllü almakta olan öğrencilerden 150 lisans son sınıf $(n=95)$ ve yüksek lisans $(n=55)$ öğrencisi rasgele örnekleme metoduyla seçilerek bu araştırmanın örneklemini oluşturmuştur. $\mathrm{Bu}$ örneklemdeki öğrencilerin yaşı 18 ile 54 arasında değişmiştir $(\overline{\mathrm{x}}=28, S S$ $=9)$. Gruptaki çoğu öğrenci, psikoloji (\% 51) veya sosyoloji (\% 20) branşlarında eğitim görmektedirler. Öğrencilerin not ortalamaları 2.00 ile 4.00 arasında değişmiştir $(\overline{\mathrm{x}}=3.33, S S=.49)$.

\section{Veri Toplama Araçları}

Öğrenciler İstatistik Kaygısı Derecelendirme Ölçeği (STARS; Cruise, Cash ve Bolton, 1985) ve İstatistiğe Karş1 Tutumlar Ölçeği'ni (ATS; Wise, 1985) yanıtlamışlar ve ayrıca geçmiş matematik tecrübelerini, kendilerinin istatistik yeteneklerini ve aldıkları istatistik dersindeki doyum düzeylerini öznel olarak derecelendirmişlerdir. STARS, 51 maddelik, 5'li Likert tipinde (Dereceli) iki ana bölümden oluşan bir kaygı ölçeğidir. İlk bölüm 23 maddeden oluşur ve istatistik kaygısını ölçmeyi hedeflerken; ikinci bölüm 28 maddeden oluşur ve istatistikle başa çıkma ile ilgilidir. Bu iki ana bölüm ölçeğin 6 alt bölümünü oluşturur. Alt bölümler İstatistik Değeri, Yorumlama Kaygıs1, Test ve Sinıf Kaygısı, Hesaplama, Yardım İsteme Korkusu, İstatistik Öğreticisi Korkusu'dur. Toplam ölçek puanı 51 ile 255 arasında değişir ve yüksek puanlar yüksek istatistik kaygısına işaret eder.

STAR'ın psikometrik özellikleri Cruise ve diğerleri (1985) tarafından incelenmiştir. İstatistik bölümünden 10 doktora öğrencisi ve öğretim üyesine ölçek maddeleri ve maddelerin ait oldukları alt bölümler sorulmuş ve hemfikirlik katsayılarının .60 ile 1.00 arasında değiştiği $(\bar{x}=.91)$ bulunmuştur. $\mathrm{Bu}$ da ölçeğin içerik geçerliğine iyi bir kanıt olmuştur. Yap1 geçerliği 1150 öğrenci üzerinde temel bileşenler analizi (TBA) yolu ile 
incelenmiş ve ölçeğin 6 alt bölümden oluştuğu bulunmuştur. $\mathrm{Bu}$ alt bölümlerin yükleme katsayıları da .48 ile .86 arasında değişmiştir. STAR'ın uygunluk geçerliği ise 537 öğrenci üzerinde yapılmış ve ölçeğin Matematik Kaygısı Ölçeği (Fennema ve Sherman, 1976) ile olan ilişkisinin .76 olduğu bulunmuştur. Aynı çalışmada, STARS'ın 6 alt bölümünün iç tutarlılık katsayılarının .68 ile .94 arasında değiştiği bulunmuştur (Medyan $=.88$ ): İstatistik Değeri $=.94$, Yorumlama Kaygıs1 $=.87$, Test ve Sinıf Kaygis1 $=$ .68 , Hesaplama $=.89$, Yardım İsteme Korkusu $=.80$ ve İstatistik Öğreticisi Korkusu $=.80$. Daha yeni bir çalışmada ise (Baloğlu, 2003) iç tutarlılık anlamındaki güvenirlik katsayılarının .64 ile .96 arasında değiştiği bulunmuştur.

ATS 5'li Likert tipinde 29 maddeden oluşan ve öğrencilerin istatistiğe karşı tutumlarını ölçen bir ölçektir. İstatistik alanına ( 9 madde) ve istatistik derslerine (20 madde) karşı tutumlar olmak üzere iki ana bölümden oluşur. Toplam test puanı 29 ile 145 arasında değişmekte ve her iki bölümde de yüksek puanlar olumsuz tutumlara işaret etmektedir. ATS'nin psikometrik özellikleri, Wise (1985) ve Shultz ve Koshino (1998) tarafindan incelenmiştir. Testin yap1 geçerliği PCA yoluyla sınanmış ve ATS'nin "alan" ve "istatistik dersi" olarak 2 faktörden oluştuğu bulunmuştur. Bu iki faktör, ATS puanlarındaki toplam varyansın yarısını açıklamıştır. İki hafta aralıklı test-tekrara test analizleri "alan" için güvenirliğin .90, "istatistik dersi” için .82 olduğunu göstermiştir. Ek olarak, bir ay süre ile yapılan testtekrara test güvenirliğinin "alan" için .69 ve "istatistik dersi" için .67 olduğu bulunmuştur. Toplam ölçek maddelerinin iç tutarlılık anlamındaki güvenirliği ise, .93 , "alan" için .89 ve "istatistik dersi" için .94 bulunmuştur (Onwuegbuzie, 1993).

Öğrenciler öznel olarak kendi istatistik yeteneklerini 0 (en düşük yetenek) ile 100 (en yüksek yetenek) olarak derecelendirmişlerdir. Ayrıca almış olmakta oldukları istatistik dersinden ve istatistik öğretim elemanından da ne kadar doyum aldıklarını 0 ile 100 (yüksek puanlar daha yüksek doyuma işaret eder) arasında derecelendirmişlerdir.

\section{Istatistiksel Analizler}

Lisans son sınıf ve yüksek lisans öğrencileri araştırma değişkenleri açısından bağımsız $t$-testi ile karşılaştırılmış ve değişkenler arası iliş̧kiler Pearson momentler çarpımı korelasyon katsayısı ile incelenmiştir. İstatistik tutumlar boyutundaki ölçekler kombinasyonunun istatistik kaygısı boyutunda hangi ölçekler kombinasyonu ile ilişkili olduğunu tespit etmek amacıyla kanonik korelasyon analizi kullanılmıştır. Kanonik korelasyon iki gurup arasındaki ilişkinin yapısını inceleyen parametrik bir analiz olup birden fazla bağımsız ve birden fazla bağımlı değişken arasındaki ilişkinin incelenmesi durumunda kullanılır (Stevens, 1986; Tabachnick ve Fidell, 
2001; Thompson, 1984). Bu çalışmada istatistik kaygısının altı boyutu çoklu bağımlı değişken profili olarak alınmış ve istatistiğe karşı tutumların iki boyutu da çoklu bağımsız değişken profili olarak kullanılmıştır. Herhangi bir veri tabanı için oluşturulabilecek kanonik değişken sayısı iki değişken takımından küçük olanı kadardır (Onwuegbuzie, 1998a). Bu çalışmada da iki değişken takımından küçük olan istatistiğe karşı tutumlar takımı iki değişkenden oluştuğuna göre iki kanonik değişken oluşturulmuştur.

\section{BULGULAR}

Araştırmanın kısıtlı olan örneklem sayısını arttırmak için lisans son sınıf ve yüksek lisans öğrencileri birleştirilmiştir. Bu iki grubun homojenliğini test etmek için iki grup araştırma değişkenleri boyutunda istatistiksel olarak karşılaştırılmış ve aralarında, yaş değişkeni haricinde, fark olmadığ 1 saptanmıştır (Tablo 1).

Tablo 1. Lisans Son Sinıf ve Yüksek Lisans Öğrencilerinin Karşılaştırılması

\begin{tabular}{|c|c|c|c|c|c|}
\hline Değişkenler & $\begin{array}{l}\text { Lisans } \mathrm{S} \\
(n=95)\end{array}$ & Sinif & $\begin{array}{l}\text { Yüksek Lisans } \\
(n=55)\end{array}$ & & \\
\hline & $\overline{\mathrm{x}}$ & $S S$ & $\bar{x}$ & $S S$ & $t^{*}$ \\
\hline $\begin{array}{l}\text { İstatistik } \\
\text { Kaygıs1 }\end{array}$ & 127.80 & 34.42 & 126.15 & 34.30 & .28 \\
\hline $\begin{array}{l}\text { İstatistik } \\
\text { Tutumu }\end{array}$ & 78.66 & 18.54 & 73.53 & 20.45 & 1.57 \\
\hline Yaş & 26.96 & 7.23 & 36.60 & 9.74 & $-4.41 *$ \\
\hline $\begin{array}{l}\text { İst. } \\
\text { Yeteneği }\end{array}$ & 61.05 & 20.34 & 64.96 & 21.30 & -1.17 \\
\hline Doyum & 65.68 & 18.94 & 68.60 & 19.82 & -.89 \\
\hline
\end{tabular}

İstatistik kaygısının alt ölçekleri (İstatistik Değeri, Yorumlama Kaygısı, Test ve Sinıf Kaygıs1, Hesaplama, Yardım İsteme Korkusu, İstatistik Öğreticisi Korkusu) ile istatistiğe karşı tutumların iki alt ölçeği (istatistik alanına ve istatistik derslerine karşı tutumlar) arasındaki ilişki ve bütün alt ölçekler arasındaki ilişkiler Pearson-moment Korelasyon Katsayısı ile incelenmiş ve değişkenler arasında yüksek düzeyde manidar ilişkiler olduğu bulunmuştur. (Tablo 2).

Bir grup istatistik kaygısı değişkeni ile bir grup istatistiğe karşı tutumlar değişkeni arasında kanonik korelasyonu bulmak için SPSS-CANCORR fonksiyonu kullanılarak kanonik korelasyon hesaplanmıştır. İstatistik kaygı takımı, istatistik değeri, yorumlama kaygısı, test/sınıf kaygıs1, hesaplama, 
yardım isteme korkusu, istatistik öğreticisi korkusu değişkenlerinden oluşmuştur. İstatistiğe karşı tutumlar takımı ise istatistik alanına ve istatistik derslerine karşı tutumlar değişkenlerinden oluşmuştur. İki takımdan değişken sayısı daha az olan istatistiğe karşı tutumlar takımı iki değişkenden oluştuğu için iki kanonik korelasyon hesaplanmıştır. İki kanonik değişken için elde edilen veriler Tablo 3’te verilmiştir.

Tablo 2. İstatistik Kaygısı ve İstatistiğe Karşı Tutumlar Ölçek ve Alt Ölçekleri Arasındaki İlişki

\begin{tabular}{llllllllll}
\hline \multicolumn{1}{c}{ Değişkenler } & & & & & & \\
\hline & 1. & 2. & 3. & 4. & 5. & 6. & 7. & 8. & 9. \\
\hline 1.İstatistik Kaygısı & - & & & & & & & & \\
2. İstatistiğe Karşı & .72 & - & & & & & & & \\
Tutumlar & & & & & & & & & \\
3. İstatistik Değeri & .85 & .84 & - & & & & & & \\
4. Yorumlama Kaygısı & .76 & .36 & .41 & - & & & & \\
5. Test ve Sınıf Kaygısı & .79 & .45 & .49 & .69 & - & & & \\
6. Hesaplama & .85 & .63 & .73 & .54 & .59 & - & & & \\
7. Yardım İsteme & .65 & .29 & .38 & .63 & .52 & .50 & - & & \\
Korkusu & & & & & & & & & \\
8. İstatistik Öğreticisi & .74 & .50 & .64 & .44 & .47 & .62 & .43 & - & \\
Korkusu & & & & & & & & & \\
9. Tutum-İstatistik Alanı & .52 & .93 & .74 & .18 & .26 & .44 & .14 & .35 & - \\
10. Tutum-İstatistik & .82 & .81 & .75 & .55 & .63 & .75 & .45 & .59 & .54 \\
Dersi & & & & & & & & &
\end{tabular}

** Korelasyonlar $.25<.01$ düzeyinde anlaml1.

* Korelasyonlar .18 ile .25 arası .05 düzeyinde anlamlı.

Yukarıdaki tabloda değişkenler ile iki kanonik değişken arasındaki korelasyonlar, standardize edilmiş kanonik değişken katsayıları, kanonik değişken tarafindan açıklanan takım-içi varyans (varyans yüzdesi), fazlalıklar (redundancy) ve kanonik korelasyonlar verilmiştir. 
Tablo 3. Kaygı ve Tutum Değişkenleri Arasındaki Korelasyonlar, Standardize Edilmiş Kanonik Katsayllar, Kanonik Korelasyonlar, Varyans Yüzdeleri ve Fazlalıklar

\begin{tabular}{lccll}
\hline & \multicolumn{2}{l}{ 1. Kanonik Değişken } & \multicolumn{2}{l}{ 2. Kanonik Değişken } \\
\cline { 2 - 5 } & Korelasyon & Katsayı & Korelasyon & Katsayı \\
\hline Kaygı takımı & & & & \\
İstatistik Değeri & -.97 & -.76 & -.22 & -1.24 \\
Yorumlama Kaygısı & -.55 & -.06 & .56 & .23 \\
Test/Sınıf Kaygısı & -.65 & -.17 & .53 & .35 \\
Hesaplama & -.84 & -.21 & .38 & .67 \\
Yardım İsteme Korkusu & -.44 & .06 & .48 & .15 \\
İstatistik Öğreticisi Korkusu & -.66 & .03 & .28 & .34 \\
Varyans Yüzdesi & .50 & & .18 & Toplam $=.68$ \\
Fazlalık & .37 & & .06 & Toplam $=.43$ \\
Tutum takımı & & & & \\
Alan & -.79 & -.40 & -.61 & -1.12 \\
Ders & -.94 & -.73 & .33 & .94 \\
Varyans Yüzdesi & .76 & & .24 & Toplam = 1.0 \\
Fazlalık & .56 & .08 & Toplam = \\
Kanonik Korelasyon & .86 & & .57 & \\
\hline
\end{tabular}

Kanonik korelasyonlardan ilki $.86 \quad(\% \quad 74$ örtüşen varyans; $\left.\chi_{(12)}^{2}=254.03, p<.001\right) \quad$ ikincisi.57 $\quad(\% \quad 33$ örtüşen varyans; $\left.\chi^{2}{ }_{(5)}=57.69, p<.001\right)$ bulunmuştur. Her iki kanonik korelasyonunda istatistiksel olarak anlamlı bulunması, bağımlı değişken takımındaki değişkenlerle bağımsız değişken takımındaki değişkenler arasındaki değişkenliğin istatistiksel açıdan anlamlı düzeyde örtüştüğüdür. Birinci kanonik değişken çifti kaygı takımındaki varyansın \% 50'sini ve tutum takımındaki varyansın \% 76'sını; ikinci kanonik değişken çifti kaygı takımındaki varyansın \% 18'ini ve tutum takımındaki varyansın \% 24'ünü çıkarmıştır. İki kanonik değişken birlikte kaygı takımındaki varyasın \%68'ini açılarken tutum takımındaki varyansın ise tamamını açıklamıştır. Kısaca, toplam varyans ve toplam fazlalık yüzdeleri her iki kanonik değişken çiftinde de kanonik değişkenlerin birbiriyle ilişkili olduğunu göstermektedir. Yani istatistiğe karşı takınılan tutumlar ile istatistik kaygısı arasındaki ilişki anlamlı düzeydedir. 
Kanonik korelasyon analizinde değişkenlerin doğrusal kombinasyonu ile kanonik değişkenler oluşturulur. Yükleme matrisinde .30 ve üzerinde yükleme yapan değişkenler o kanonik değişkeninin parçası sayılırken .30'dan aşağı yükleme yapan değişkenler kanonik değişkenin parçası sayılmazlar (Tabachnick ve Fidell, 2001). Bu çalışmada daha hassas olunarak .40 ve üzeri yükleme yapan değişkenler kanonik değişkenin parçası olarak dikkate alınmıştır. Birinci kanonik değişkendeki tüm değişkenler .40'dan daha yüksek yükleme yapmışlardır. Dolayısıyla, istatistik değeri, yorumlama kaygısı, test ve sınıf kaygısı, hesaplama, yardım isteme korkusu, istatistik ögreticisi korkusu ile istatistik alanına ve istatistik derslerine karşı tutumlar arasında anlamlı ilişki bulunmuştur. Bulunan korelasyonların yönü dikkate alındığında, istatistik alanına ve istatistik dersine karşı olumlu tutum besleyen öğrenciler istatistiğe daha çok değer veren, yorumlama, test ve sinıf kaygıları daha düşük, istatistiksel hesaplamalar yapabileceklerine inanan ve yardım almaktan ve istatistik öğreticisinden korkmayan öğrencilerdir.

İkinci kanonik değişkende ise kaygı takımındaki yorumlama kaygısı, test ve sinıf kaygis1, hesaplama ve yardım isteme korkusu ile tutum takımındaki istatistik alanına karşı tutumlar değişkenleri yüksek yükleme yapmışlardır. Yani, istatistik alanına karşı olumlu tutum besleyen öğrenciler yorumlama ve test/sınıf kaygısı yüksek, yardım istemekten korkan öğrenciler olarak bulunmuşlardır.

\section{YORUM ve TARTISMA}

İstatistik kaygısı literatürde çok boyutlu bir yap1 olarak ortaya konmuştur. Aynı şekilde istatistiğe karşı takınılan tutumlar da iki boyutlu olarak incelenmiştir. Bu tür iki değişken arasındaki ilişkinin incelenmesi için en uygun parametrik metot kanonik korelasyondur ki bu çalışmada kullanılmıştır. Birçok parametrik analiz gibi, kanonik korelasyon analizinde de gerekli değişken/örneklem oranı değişkenlerin güvenirliğine bağlıdır. Bu çalışmada kullanılan toplam sekiz değişkenin ortalama güvenirlikleri .80'in üzerindedir. Bu durumda her bir değişken için on veri üzerinden hesaplanırsa örneklemin en az seksen öğrenciden oluşması gerekmekteydi. Araştırmanın örneklem sayısını arttırmak için lisans son sınıf ve yüksek lisans öğrencileri birleştirilmiştir ve bu iki grup tek bir grup olarak incelenmiştir. Fakat ana analizlerden önce iki grubun homojenliği test edilmiş ve gerçekten de araştırma değişkenleri boyutunda, yaş değişkeni hariç, hiçbir farkl1lık olmadığı saptanmıştır. Yüksek lisans öğrencilerinin yaş ortalamasının lisans öğrencilerinden daha yüksek olduğu anlaşılmaktadır. Yüksek lisans öğrencilerinin lisans son sınıf öğrencilerinden yaşça büyük olmaları da oldukça doğal bir sonuçtur. Kısaca, çalışmadaki örneklem sayısı kanonik korelasyon analizi için yeterli düzeydedir denilebilir. 
Korelasyon katsayıları incelendiğinde hemen hemen bütün ikili ilişkilerin istatistiksel anlamda manidar olduğu bulunmuştur. $\mathrm{Bu}$ da bize istatistiğe karşı takınılan tutumlar ile istatistik kaygısının yakın ilişkisini göstermektedir. İstatistik kaygısı ile istatistiğe karş1 takınılan tutumların yüksek derecede ilişkili olduğu literatürde de rastlanan bir sonuçtur (Bkz. Wise, 1985; Zanakis \& Valenzi, 1997). Bu çalışmada, en yüksek ilişkiler istatistik değeri ve hesaplama ile istatistik dersine karşı takınılan tutumlar arasındaki ilişkilerdir. İstatistik derslerinde oldukça fazla hesaplama yapıldığı dikkate alınırsa istatistik dersine karşı takınılan olumsuz bir tavrın kendisini en çok bu alanda göstermesi de hiç şaşırtıcı olmayacaktır.

Kanonik korelasyon analizi sonucunda istatistiğe karşı takınılan tutumlar ile istatistik kaygısı arasındaki ilişkinin anlamlı olduğu bulunmuştur. Sonuç istatistik alanına veya spesifik olarak istatistik dersine karşı olumsuz tutum besleyen öğrencilerin kaygı düzeylerinin yüksek olduğunu olarak yorumlanabilir. $\mathrm{Bu}$ durumda, istatistik öğreticilerinin yapması gereken ilk iş öğrencilerin tutumlarını ölçmek ve olumsuz tutumları olan öğrencilere özel ilgi göstererek onların tutumlarını değiştirmeye çalışmak olmalıdır. Bu yönde yapılabilecek bazı faaliyetler literatürde oldukça geniş bir yer tutmaktadır (Bkz. Baloğlu, 2001; Blalock, 1987). Sadece ders içeriğine yoğunlaşmak istatistik derslerinde optimal öğrenme için yeterli görülmemektedir. Sonuç olarak istatistik dersine yönelik olumsuz tutuma sahip olan öğrencilerin istatistik dersi yönelik kaygılarının yüksek olduğu bulgusuna ulaşılmıştır. Yüksek kaygının öğrenme üzerindeki olumsuz bozucu etkileri bilinen bir gerçektir. Bu nedenle istatistik dersini okutan öğretmenlerin, öğretim üyelerinin öncelikli olarak öğrencilerin duyuşsal alan davranışları ile ilgilenerek istatistiğe yönelik olumsuz duygu ve tutumlarını olumlu yönde değiştirmeyi amaçlamalıdır. 


\section{KAYNAKLAR}

Auzmendi, E. (1991, April). Factors related to attitudes toward statistics: A study with a Spanish sample. (ERIC Document Reproduction Service No. ED333049)

Baloğlu, M. (2003). Individual differences in statistics anxiety among college students. Journal of Personality and Individual Differences, 34, 855-865.

Baloğlu, M. (2002). Psychometric properties of the Statistics Anxiety Rating Scale. Psychological Reports, 90, 315-325.

Baloğlu, M. (2001). An application of structural equation modeling techniques in the prediction of statistics anxiety among college students. Unpublished doctoral dissertation, Texas A\&M University-Commerce.

Blalock, H. M. (1987). Some general goals in teaching statistics. Teaching Sociology, 15, 164-172.

Connor-Greene, P. A. (1993). From the laboratory to the headlines: Teaching critical evaluation of press reports of research. Teaching of Psychology, 20, 167-169.

Cruise, R. J., Cash, R. W., \& Bolton, D. L. (1985, August). Development and validation of an instrument to measure statistical anxiety. Paper presented at the annual meeting of the American Statistical Association Statistics Education Section. Las Vegas, Nevada.

Feinberg, L. B., \& Halperin, S. (1978). Affective and cognitive correlates of course performance in introductory statistics. Journal of Experimental Education, 46, 11-18.

Fennema, E, \& Sherman, J. A. (1976). Fennema-Sherman Mathematics Attitude Scale: Instruments designed to measure attitudes toward the learning of mathematics by females and males. JAS Catalog of Selected Documents in Psychology, 6, 31 .

Fenster, M. J. (1992). Statistics courses and adult learners: Assessing potential problems. Journal of Studies in Technical Careers, 14, 11-22.

Onwuegbuzie, A. J. (1998a). Statistics anxiety: A function of learning style? Research in the Schools, 5, 43-52.

Onwuegbuzie, A. J. (1998b). The dimensions of statistics anxiety: A comparison of prevalence rates among mid-southern university students. Louisiana Educational Research Journal, 23, 23-40.

Onwuegbuzie, A. J. (1995). Statistics test anxiety and female students. Psychology of Women Quarterly, 19, 413-418. 
Onwuegbuzie, A. J. (1993). The interaction of statistics test anxiety and examination condition in statistics achievement of post-baccalaureate non-statistics majors. Unpublished doctoral dissertation, the University of South Carolina.

Onwuegbuzie, A. J., DaRos, D., \& Ryan, J. M. (1997). The components of statistics anxiety: A phenomenological study. Focus on Learning Problems in Mathematics, 19, 11-35.

Royse, D., \& Rompf, E. L. (1992). Math anxiety: A comparison of social work and non-social work students. Journal of Social Work Education, $28,270-277$.

Shultz, K. S., \& Koshino, H. (1998). Evidence of reliability and validity for Wise's Attitude Toward Statistics Scale. Psychological Reports, 82, 27-31.

Stevens, J. (1986). Applied multivariate statistics for the social sciences. Hillsdale, NJ: Lawrence Erlbaum Associates.

Swanson, J. C., Meinert, D. B., \& Swanson, N. E. (1994). Business communications: A highly valued core course in business administration. Journal of Education for Business, 69, 235-239.

Tabachnick, B. G. \& Fidell, L. S. (2001). Using multivariate statistics (4th ed.). Needham Heights, MA: Allyn \& Bacon.

Thompson, B. (1984). Canonical correlation analysis. Newbury Park, CA: Sage Publications.

Waters, L. K., Martelli, T. A., Zakrajsek, T., \& Popovich, P. M. (1988). Attitudes toward statistics: An evaluation of multiple measures. Educational and Psychological Measurement, 48, 513-516.

Wise, S. L. (1985). The development and validation of a scale measuring attitudes toward statistics. Educational and Psychological Measurement, 45, 401-405.

Woehlke, P. L., \& Leitner, S. W. (1980). Gender differences in performance on variables related to achievement in graduate level educational statistics. Psychological Reports, 41, 1119-1125.

Zanakis, S. H., \& Valenzi, E. R. (1997). Student anxiety and attitudes in business statistics. Journal of Education for Business, 73, 10-16.

Zeidner, M. (1991). Statistics and mathematics anxiety in social students: Some interesting parallels. British Journal of Educational Psychology, 61, 319-328. 